\title{
A escola e a educação inclusiva: professoras e alunos em cena
}

\author{
Carla Mercês Rocha Jatobá Ferreira* \\ Tatiane Felipe Lopes**
}

\section{Resumo}

O artigo analisa tópicos da educação inclusiva relativos a professoras e alunos. Para isto apresenta desafios presentes no interior de duas escolas públicas de uma cidade do interior mineiro destacando elementos discursivos, situaçóes observadas e opiniōes emitidas por professoras e alunos das respectivas escolas quanto à educação inclusiva. Estes dados se configuram como resultado de uma pesquisa desenvolvida com o apoio do Programa de Iniciação Científica da Universidade Federal de Ouro Preto, no período 2011-2013. A pesquisa é qualitativa e os dados foram coletados através de observaçôes sistemáticas e entrevistas semiestruturadas. Os resultados apresentados no artigo apontam desafios ligados ao desconforto e queixa pelo despreparo pedagógico para o exercício de uma educação inclusiva, por parte das professoras. $\mathrm{O}$ artigo ao abordar a educaçáo inclusiva argumenta em favor de uma melhor compreensão do cotidiano escolar, quando este se apresenta permeado por situaçôes que podem ser tratadas de maneira inclusiva. Em modo conclusivo, destaca a urgência de mudanças no olhar docente sobre aquelas crianças que demandam atenção diferencial, atentando-se para que "déficits" sejam minimizados e possibilidades educativas buscadas, como possível saída para o imobilismo que transparece nos pronunciamentos docentes.

Palavras-chave: Inclusão escolar; Professoras; Alunos.

* Professora doutora da Universidade Federal de Ouro Preto, Ouro Preto, Minas Gerais, Brasil.

** Graduada em Pedagogia pela Universidade Federal de Ouro Preto, Ouro Preto, Minas Gerais, Brasil. 


\section{The school and inclusive education: teachers and students in scene}

\section{Abstract}

The article analyzes topics of inclusive education for teachers and students. Elements of discursive situations are brought to light in the challenges and daily life of two public schools in a city of Minas Gerais (Brazil) and are highlighted in the text, vis $-\grave{a}$-vis, field observations and opinions expressed by teachers and students of those schools concerning inclusive education. Data was obtained as the result of a survey carried out with the support of the Scientific Initiation Program (Programa de Iniciação Cientifica) of the Federal University of Ouro Preto, in the period 2011-2013. The research is qualitative and uses data collected through systematic observations and semi-structured interviews. Results presented in the article point to the discomfort and complaints by the teaching staff, with prevailing feelings of unpreparedness for the exercise of inclusive education. The article argues for a better understanding of everyday school life, when permeated by situations that could be addressed in an inclusive manner. In conclusion it highlights the urgency of changes in the modes the teaching staff regards those children who need differential attention, so that "deficits" could be minimized and educational possibilities sought, as a possible way out of the situation of immobility that transpires through teachers pronouncements.

Keywords: School inclusion; Teachers; Students.

\section{Introdução}

O oferecimento de uma educação pública de qualidade tem sido uma demanda constante das populaçôes em países democráticos. Presenciamos desde os anos 90 do século passado a propagaçáo de políticas inclusivas para países considerados em desenvolvimento, visando à efetivação dos direitos humanos. As políticas atuais para a educação inclusiva declaram o acesso à educação pública para todos, independente das condiçôes socioeconômicas, de etnia e deficiências.

A educação inclusiva é considerada como uma estratégia política de acolhimento da diversidade de estudantes nas escolas. Consequentemente aspira à redução de processos exclusivos que perduram nos ambientes de convívio humano. As atitudes humanas obscurecidas que revestem o outro de superstiçóes, estereótipos e categorizaçôes são ilustrativas de movimentos de exclusão que afetam a vida das pessoas em situação de deficiência (GARDOU, 2011). Os processos de exclusão referentes aos considerados diferentes são aqueles que se ancoram em antigos paradigmas relativos às concepçóes organicistas e biológicas sobre a deficiência, e portanto, impeditivos de novas interpretaçôes das diferenças e da interação social (OLIVEIRA; DRAGO, 2012).

Neste artigo abordamos a educação inclusiva como o processo que garante a presença de todas as crianças em escolas comuns, "mesmo as classificadas como 
aquelas que têm necessidades especiais" (Ainscow, 2009, p. 13). Para isto, as escolas precisam passar por processos transformadores, apoiados em novos paradigmas e novas concepções sobre os processos de aprendizagem (OLIVEIRA, 2006; KASSAR, 2011). Outro tópico destacado para a realização da educação inclusiva é a necessidade de professores sensíveis à diversidade dos alunos e a presença de novos instrumentos de trabalho em salas de aula, implementando "uma práxis que contemple diferentes metodologias" (Sanches, 2005, p.132). A educação inclusiva promove uma nova concepção de escola onde especiais seriam os dispositivos (recursos humanos e materiais) disponibilizados "para atender à diversidade de seu alunado" (Glat; Blanco, 2007, p. 17).

Alguns estudos comentam a influência de múltiplos elementos na gestão da educação inclusiva (MAGALHÃES; STOER, 2006; FERREIRA, 2006; OLIVEIRA, 2007; MACHADO, 2009; PLETSCH, 2010; TREMBLAY, 2012). Outros investigam a presença de crianças com deficiência intelectual em escolas regulares. Entre outros aspectos, tais estudos apontam dificuldades interativas entre crianças classificadas como deficientes mentais (DM) e seus colegas (BATISTA; ENUMO, 2004), como também marcas resultantes de um percurso escolar que não chegou a se inscrever apontando à insuficiência da legislaçáo e de teorias para ofertar o lugar de aluno (VASQUES; MOSCHEN; GURSKI, 2013;) e a importância da presença de processos afetivos na relação com o conhecimento e aprendizagem escolares (MATTOS, 2012).

$\mathrm{Na}$ medida em que a educação inclusiva surge em discursos midiáticos e configura-se como política ampla, trazer aspectos relativos ao cotidiano de professores e alunos se faz necessário por revelarem dinâmicas internas presentes nas instituiçóes, como nos aponta Kassar (2011) ao ressaltar a necessidade de "olhar dentro da escola e identificar diferentes desafios" (p. 73). Nesta direção, o objetivo do artigo consiste em discutir aspectos desafiantes da educação inclusiva ressaltando situações observadas em duas escolas públicas de uma cidade do interior mineiro e falas e opinióes emitidas por professoras e alunos das respectivas escolas. Os dados se configuram como resultados parciais ${ }^{1}$ de pesquisa desenvolvida com o apoio do Programa de Iniciação Científica da Universidade Federal de Ouro Preto, no período 2011-2013.

\section{Metodologia}

A pesquisa caracterizou-se como qualitativa, uma vez que estávamos motivadas pelo princípio de que pequenos fatos e detalhes do cotidiano escolar poderiam ser valiosos para "estabelecer uma compreensão mais esclarecedora do nosso objeto de estudo" (BOGDAN; BIKLEN,1994, p. 49). Entretanto, nossa preocupação principal foi a discussão dos desafios para a inclusão escolar em duas escolas públicas do Estado de Minas Gerais.

Tivemos como sujeitos sete crianças (indicadas pela escola, pelo critério de apresentarem alguma dificuldade de aprendizado ou mesmo alguma deficiência física e/ou mental), suas respectivas professoras, seus pais, e as diretoras das duas escolas ${ }^{2}$. Neste artigo, crianças e professoras têm seus nomes omitidos. As professoras são designadas por algarismos romanos e as crianças por nomes fictícios. 
Como instrumentos para a coleta de dados, utilizamos observações sistemáticas e entrevistas semiestruturadas. Iniciamos pelas observaçôes do cotidiano das escolas envolvidas com a inclusão. As mesmas tiveram como ambientes o pátio e salas de aula. Cada criança foi observada duas vezes em cada ambiente, diferenciando o tempo destinado às observações. No pátio, as observaçôes duraram vinte minutos, período de tempo destinado ao recreio. Para as salas, foi disponibilizado maior espaço de tempo, uma hora, tornando possível o acompanhamento integral de uma rotina de estudos/atividades.

$\mathrm{Na}$ segunda etapa, realizamos entrevistas semiestruturadas com professoras, pais, alunos e diretoras das escolas. No artigo, discorremos sobre entrevistas com professoras, diretoras e alunos. As entrevistas não obedeceram a um espaço temporal determinado. Estiveram sujeitas ao envolvimento e disposição demonstrados pelos sujeitos. Com professoras e diretoras possibilitou-nos a identificação de atitudes, dificuldades e impressóes relativas ao trabalho com a educaçáo inclusiva. Diante das crianças encontramos maior facilidade nas entrevistas, pois mesmo demonstrando timidez, buscaram se expressar e nos contar sobre dificuldades escolares, temores e sentimentos de pertença à escola. Escolhemos a entrevista semiestruturada, uma vez que nos permitiu certa liberdade na condução da conversa e as perguntas " são abertas e podem ser respondidas dentro de uma conversação informal” (MARCONI; LAKATOS, 2005, p. 199).

\section{Apresentação e discussão dos resultados}

\section{I - Conversando com as professoras}

No artigo discutiremos aspectos da educação inclusiva relativos aos desafios enfrentados pelas professoras e alunos, abordando resultados da pesquisa referentes aos pronunciamentos destes sujeitos.

Algumas impressóes nos acompanharam durante conversas informais e entrevistas junto às professoras: elas estiveram receosas para comentar sobre o trabalho pedagógico e posicionar-se sobre a inclusão das crianças. Na outra escola, percebemos a impaciência para conversar conosco, demonstrando desinteresse pelo assunto. As impressões iniciais foram se configurando como índices e sinais da insatisfação docente com procedimentos políticos e educacionais, ou a ausência dos mesmos, no encaminhamento da educação inclusiva.

Das observaçóes e entrevistas ressaltamos, inicialmente, falas das duas gestoras (diretora e vice) de uma das escolas. Elas demonstraram alheamento sobre as políticas públicas voltadas à inclusão e sua definição. A preocupação com outros temas que perpassam o cotidiano escolar parecia ocupá-las, e quando conversávamos sobre a inclusão das crianças, presenciávamos a recusa em tratar o assunto. A impressão foi comprovada ao indagá-las sobre o recebimento de materiais municipais ou federais sobre a inclusão. A diretora e a vice nos relataram que receberam algum material, mas náo sabiam do que se tratava. $\mathrm{O}$ alheamento e a falta de curiosidade presentes nas falas das gestoras pareceu-nos preocupante, pois estas funçôes são peças de destaque 
para a efetivação de um sistema inclusivo. Sant'Ana (2005) em estudo sobre as concepçôes de professores e diretores sobre a educação inclusiva destaca a importância da atuação dos diretores para uma direção inclusiva na educação:

esse profissional precisa ser atuante, promovendo açóes que envolvam o acompanhamento, discussóes e avaliaçóes em conjunto com os participantes do projeto educacional, a fim de exercitar as dimensôes educacional, social e política, inerentes à sua função. (SANT'ANA 2005, p. 229).

Outrossim, consideramos que os aspectos comentados são ilustrativos de conflitos apontados por ANJOS, ANDRADE e PEREIRA (2009) quanto à morosidade nos encaminhamentos das políticas educacionais inclusivas em municípios brasileiros e também sobre o pouco conhecimento dos atores educacionais sobre o processo inclusivo(FREITAS, 2009; BARBOSA, SOUZA, 2010).

Quanto às entrevistas, percebemos em alguns depoimentos a noção de inclusão relacionada a aspectos estruturais, onde se evidencia a ausência de mudanças físicas e de material necessário para atendimento a alunos com dificuldades visuais e auditivas. Uma das professoras explicitou sua queixa no tocante ao suporte pedagógico:

Precisamos de especialista que dê uma orientação para a gente. O Magistério não ensina isso para a gente, a gente náo está preparada. A possibilidade de ter um suporte, e converso muito com a pedagoga. A gente não tem retorno. A inspetora vem uma vez por mês, não pergunta nada aos professores. Não há acompanhamento pela Secretaria Municipal de Educação. Eu me preocupo mais com os que não sabem. (Profa. I)

Interpretamos os pontos mencionados como relacionados a aspectos políticos do processo inclusivo, sobre os quais a professora demonstrou consciência do seu despreparo para a intervenção pedagógica necessária. Esta noção de despreparo tem sido constante em trabalhos que discutem a inclusão (GLAT, BLANCO, 2007; ANJOS, ANDRADE, PEREIRA, 2009; MACHADO, 2009; PLAISANCE, 2009). A professora ao expressar sua demanda por suporte pedagógico vai ao encontro de um dos princípios básicos da educação inclusiva: a formação dos professores e o suporte para os desafios impostos por um sistema educativo inclusivo, como esclarece Dorziat (2013, p.990) "nesse novo modelo os educadores são [...] instados a rever seus conceitos, mas sem desconsiderar a presença e a importância de especialistas que passam a integrar os serviços de suporte educacional".

As professoras têm clareza sobre a necessidade de mudanças no fazer pedagógico com crianças que apresentam dificuldade nos processos de aprender. Assinalam que o trabalho pedagógico não se realiza homogeneamente, pois a presença de crianças com necessidades educativas especiais ${ }^{3}$ reivindica planejamento e ações específicas impossíveis de acontecer perante o desconhecimento teórico dos docentes e da conjuntura institucional das escolas.

Destacamos no depoimento de outra professora a sugestão de implementação de um questionário como dispositivo que possibilite um melhor conhecimento do aluno com "necessidade especial", pois segundo a mesma "os pais não apresentam 
de fato qual a necessidade e a deficiência do filho provocando dificuldade para trabalhar com eles" (Profa. III). Concebemos a sugestão como originária da queixa do despreparo profissional e relativa ao desconhecimento da escola sobre problemáticas apresentadas pelas crianças. A sugestão nos leva a estabelecer associaçóes com outros estudos (DORZIAT, 2013) quando enfatizam a permanência de visóes clínica e técnica sobre as dificuldades de aprendizagem das crianças.Podemos relacioná-la com a permanência da concepçáo da vertente médico-pedagógica para a deficiência (JANNUZZI, 2004) na qual consideraçóes médicas podem assinalar e prever o processo de aprendizagem. Apontamos juntamente com outros pesquisadores (LAPLANE, 2006; DORZIAT, 2013) que a influência destas concepções no universo escolar impede o surgimento de processos pedagógicos inovadores que reflitam e abdiquem de visôes tradicionais sobre o aprender de crianças com necessidades educativas especiais, encarado persistentemente como processo deficitário.

Concebemos que a ausência de espaços discursivos e planejamento coletivo no trabalho pedagógico contribuem para a permanência do imaginário de dificuldades nas concepçôes docentes sobre a educação e sobre os processos relacionais com crianças que apresentam necessidades educativas especiais. Corroborando com esta ideia, destacamos o pensamento das professoras entrevistadas, quando consideram os pais como náo aliados no processo de aprendizagem dos filhos. Julgamos tal concepção como prejudicial à educação inclusiva, pois professores, pais e alunos deveriam aliar-se no enfrentamento dos processos excludentes que ainda envolvem o acesso à educação das classes e grupos mais desfavorecidos economicamente no Brasil (PATTO, 2000; 2007).

As professoras não cursaram e não cursavam formação continuada, ponto recorrente surgido em suas falas em diversos momentos como no comentário de uma delas sobre seu aluno: "Na sala, está sempre quieto, às vezes não participa das aulas. Tem outros alunos na sala com atraso na aprendizagem, mas ele tem alguma coisa a mais. Não sei dizer ao certo, pois não tenho curso na área”.

Para além dos sentimentos verbalizados, percebemos resistência, angústia e queixa pelo desamparo diante da ausência de orientaçóes pedagógicas pela Secretaria Municipal de Educação. As professoras entrevistadas não se referiram à existência de momentos coletivos de discussão sobre o trabalho pedagógico com crianças com necessidades educativas especiais. Neste movimento de formação continuada consideramos que encontros casuais, conversas corriqueiras sobre os alunos nos espaços escolares são processos inerentes à atividade docente. Destacamos a importância, como outros pesquisadores (MÜLLER,2010; PLETSCH, 2010; SANCHES, 2011) da busca por processos interlocutórios nos quais oportunidades de discussão sobre as práticas pedagógicas se materializem. Contudo, ressaltamos que a presença de "interlocutores qualificados que possam contribuir no avanço teórico-metodológico da escola, na tentativa de constituir novos contornos à organização escolar e a prática pedagógica" (Oliveira;Drago, 2012, p.358) pode se constituir como possibilidade enriquecedora e formadora.

Destacamos no grupo das professoras a iniciativa de uma delas (professora- II período da educaçáo infantil) que diante de uma criança com deficiência auditiva 
procurou um curso de Libras relatando que "a interação com o aluno melhorou muito depois de ter iniciado o curso". O depoimento nos lembrou uma passagem do livro Vendo Vozes cujo autor, o neurologista americano Oliver Sacks, conta-nos que antes de ter interesse intelectual pela forma de comunicação entre os surdos (língua de sinais) percebia seus pacientes surdos pelo viés médico como "ouvidos doentes", mas após contato com a literatura sobre surdez assinala:

Comecei a vê-los sob uma luz diferente, especialmente quando avistava três ou quatro deles fazendo sinais, cheios de uma vivacidade, uma animação que eu não conseguira perceber antes. Só entáo comecei a pensar neles náo como surdos, mas como Surdos, como membros de uma comunidade linguística diferente. (SACKS, 1998,p. 16).

Sublinhamos que despreparo, iniciativas solitárias e distanciamento dos alunos, foram os desafios marcantes na análise das entrevistas com as professoras. Constataçóes semelhantes são descritas por Plaisance (2009) ao comentar dificuldades de professores diante da escolarizaçáo de crianças que demandam necessidades educacionais especiais, na França. Para o autor a presença destas em classes comuns provoca perturbaçôes nas representações tradicionais da função docente, surgindo daí resistências para o trabalho pedagógico.

Ainda queremos ressaltar nossas considerações e impressóes nos meses de contato com as professoras: pareciam pouco à vontade para falar sobre a inclusão, hesitavam em defini-la buscando as palavras com prudência. $\mathrm{O}$ distanciamento e incompreensão delas perante a legislação nos acompanharam durante o estudo. A circunstância faz lembrar Lucia De Anna quando comenta sobre a educação de crianças deficientes na Itália "é o mais grave problema que nós temos com as experiências de integração, os professores frequentemente se desencorajam e abandonam o terreno porque se sentem sós"(DE ANNA, 2003, p. 51).

Antes de passarmos a tratar das impressóes das crianças sobre suas escolas, ressaltamos a fala de uma das diretoras ao se referir à educação inclusiva:"nenhuma professora tem capacitaçáo para isto [...] vamos aprendendo no trabalho".A afirmação nos parece ilustrativa da distância entre a prática vigente nas escolas pesquisadas e recomendaçôes dos marcos legais para a educaçâo inclusiva. Um sistema educacional inclusivo reclama à comunidade escolar, saberes acadêmicos e práticos que permitam a identificação das diferenças nas aprendizagens dos alunos, principalmente daqueles que apresentam entraves e rupturas nos percursos escolares (OLIVEIRA; DRAGO, 2012).

\section{II - As crianças, principais sujeitos do processo de inclusão escolar}

Para a Sociologia da Infância o estudo da criança tornou-se objeto de pesquisa valioso durante o começo do século XXI, pois estudar o campo educativo, abordando a escola, a família, não é mais possível sem se preocupar com a posição e valores atribuídos à criança na modernidade (SIROTA, 2006; SARMENTO, 2006). 
A inclusão escolar tem sido pesquisada por diversos ângulos, mas a participação das crianças submetidas ao processo inclusivo tem se limitado à posição de objeto de pesquisa. Para nosso estudo a escuta das crianças foi fundamental, quando concordamos com Alderson ao afirmar "reconhecer as crianças como sujeitos em vez de objetos de pesquisa acarreta aceitar que elas podem falar em seu próprio direito e relatar visóes e experiências válidas"(2005, p. 423).

Sete crianças, classificadas como portadoras de necessidades educativas especiais, participaram da pesquisa. Três delas frequentam a Escola A: Carol, Victor e Ricardo. Enquanto Roberto, André, Sílvio e Caio frequentam a Escola B.

As observaçóes foram realizadas em sala de aula e no recreio. Com as crianças, percebeu-se os desafios relativos ao incômodo, ao embaraço e à timidez quando estão diante das aprendizagens em sala de aula. No recreio foi observado que os alunos apresentavam participações interativas com colegas em brincadeiras. Também observamos em um dos sujeitos, vivências perturbadoras e provocadoras de medo e insegurança diante da ausência da mediação adulta em situações de confronto. No artigo, discutimos passagens referentes a quatro delas. Como pesquisadoras, estávamos preocupadas em registrar interesses escolares, impasses, interação com professoras e com colegas e desempenho nas atividades escolares.

Percebemos o recreio como júbilo e riqueza interativa para as crianças, nos lembrando as palavras de Delalande: "Quem não conhece pelo som de um apito de escola quando na hora do recreio os alunos saem correndo para aproveitar o mais rápido esta pequena parcela de tempo destinada às brincadeiras?"(2001, p.42). Neste estudo, tal constatação se evidenciou. No recreio seis crianças, sujeitos da pesquisa, participavam de interaçóes com outras através de brincadeiras, de jogos de futebol ou caminhavam de mãos dadas com colegas pelos espaços das escolas. Observamos o livre acesso às dependências das duas instituiçôes. Havia liberdade de movimento e familiaridade com os espaços. Esta constatação se faz valiosa para Caio, aluno do II período da Educação Infantil, que andando com ajuda de aparelho de apoio, experimentava seus percursos, utilizando rampas de madeira colocadas para lhe favorecer a locomoção. Seu caminhar era seguro e parecia convencido disto, chegando mesmo a correr e até jogar futebol. Destacamos também a solidariedade existente entre ele e os colegas do seu grupo, que o ajudavam, demonstrando correntemente alegria por tê-lo como integrante das brincadeiras.

Sabemos que estas situaçôes são significativas para crianças consideradas especiais pois ter colegas como companheiros de brincadeiras é um dado significativo para o seu bem-estar nos espaços escolares. Além disso, nossas constataçóes não são coincidentes com observaçóes de outros estudos. Neste sentido, Batista e Enumo (2004) ao realizarem um estudo sobre educação inclusiva e interação social entre companheiros em escolas da Rede Municipal de Vitória, no Espírito Santo, com três alunos diagnosticados como 'deficientes mentais' e seus colegas de classe, concluíram que "alunos portadores de necessidades educativas especiais são aceitos com menos frequência e são mais rejeitados que seus companheiros de turma de classes regulares"(p. 108). 
À semelhança do estudo acima citado, destacamos Silva (2013) que ao discorrer sobre estudos inclusivos em Portugal nos conta que em dados recolhidos em 2007, encontrou sentimentos de "inquietação e falta de respeito"(p. 182), porém em estudos posteriores foram encontrados dados significativos que demonstram além de atitudes consideradas maldosas, outras de ajuda mútua e aceitação (p. 182).

$\mathrm{Na}$ direção dos nossos resultados, salientamos o estudo desenvolvido por Tessaro et al. (2005) a respeito da visão dos alunos sem necessidades educativas especiais sobre a inclusão escolar. $\mathrm{O}$ estudo teve como sujeitos alunos do ensino regular de escolas públicas de um município no interior do Estado do Paraná. Suas conclusôes apontam para o fato de que "a maioria dos alunos sem necessidades educativas especiais é favorável à inclusão escolar e possuem sentimentos positivos em relação a este processo"(p. 113).

Atitudes semelhantes às de Caio também foram observadas com André e Roberto. Os dois foram considerados pela equipe pedagógica da escola como atingidos por retardo mental ${ }^{5}$. André frequentava a escola há dois anos, e no momento da pesquisa, estava no $2^{\circ}$ ano do ensino fundamental. Sua professora o descreveu como "extremamente tímido", e sua colocação "não sei como trabalhar com ele" foi recorrente. Quando o observamos no recreio, percebemos que participou de brincadeiras grupais como pega-pega, inclusive em alguns momentos, conduziu a brincadeira. Lanchou e conversou com colegas, e percebendo a presença de um vendedor de filtros na escola, dirigiu algumas palavras ao mesmo. Entretanto, em sala de aula, náo o percebemos da mesma maneira.Mesmo acompanhando solicitaçôes da professora relativas à busca pelo material escolar, parecia pouco à vontade e ao perceber a proximidade da professora da sua carteira demonstrava nervosismo. Nossas observaçóes ocorridas em diferentes dias letivos registraram aulas de história (acompanhando o livro didático) e matemática (resolução de problemas). A reação de André pode ser atribuída à sua dificuldade de resolução das atividades, pois na aula de matemática, quando a professora perguntou se havia dúvidas, e enfaticamente, assinalou: "agora é a hora de perguntar", percebemos que ele se movimentou na carteira, vacilante, mas não ousou perguntar.

Quando conversamos com André não o percebemos tímido. Conta-nos do seu apreço pela escola, pelos colegas e recreio. Quanto às dificuldades escolares nos diz que a professora e a mãe estão lhe ensinando a ler. Mas que não gosta de perguntar em sala de aula: "tenho medo que a professora grite comigo". Quando indagado sobre suas aspiraçôes futuras diz que seus pais querem que ele seja "um cientista", e logo em seguida lhe perguntamos o que faz um cientista, ele respondeu sem vacilar: "mexe com as coisas...ele inventa as coisas". Mas, nos conta que ele quer "trabalhar no lava-jato, como seu pai".

A reflexão sobre André nos estimula a comentar que a vivência e a frequência escolares são elementos que compóem sua experiência educativa e assim deveriam ser considerados, e a sua fala junto a nós durante este estudo nos leva a concordar com Vazques; Moschen; Gurski (2013) quando afirmam que: 
analisar a intervenção e o contexto é fundamental para repensar os sujeitos, pois o conhecimento que se pode ter deles depende diretamente de análises que integrem a historicidade das relaçóes e das instituições que forjam e sustentam formas de viver... (p. 90).

Roberto estava matriculado no $3^{\circ}$ ano do ensino fundamental frequentando a escola desde a educação infantil. Demonstrava muita desenvoltura em sua circulação pelos espaços escolares e, no momento do recreio suas atividades preferidas foram os jogos com bola. Nestes momentos nós o percebíamos feliz, rindo e participando dos lances, incentivando os colegas, e tocado por uma grande alegria quando a bola vinha em sua direção. Em sala, foi visível seu esforço para realizar as atividades sugeridas. Nas observaçôes, ocorridas em dois diferentes dias letivos, registramos atividades de matemática. A primeira observação acompanhou o registro de um jogo de boliche em equipe ocorrido anteriormente. Na segunda, acompanhamos a resoluçáo de problemas matemáticos com a operaçáo de subtraçáo. Nas observaçôes, percebemos seu embaraço diante da proximidade da professora em sua carteira, indagando-lhe, em voz alta, quanto aos resultados, ele, constrangido, respondia baixinho, os colegas acompanhavam a cena.

Em sua entrevista esteve à vontade. Contou-nos do seu apreço em vir à escola, para "brincar com os amigos e estudar". Também nos disse que gosta muito "de estudar matemática e português, mas não gosta de ciências". Perguntamos sobre as dificuldades dele em aprender, disse-nos que "tem dificuldade por isto vem ao reforço ${ }^{6}$, para estudar matemática e português". Diz que ao ter dificuldades na resoluçáo dos deveres de casa sua madrinha ajuda, e na escola, solicita ajuda da professora. Ao nos contar do afeto que sente pela mesma, nos diz num tom de desabafo, que na escola tem uma professora "que grita muito..., fico nervoso..., é melhor a gente aprender sem grito".

O ato educativo é enlaçado pelo desejo do professor de que seus alunos aprendam. André e Roberto nos dizem disto. Os meninos nos pareceram orgulhosos da condição de alunos, de vir à escola, ao reforço, de ter uma rotina escolar, de participar das atividades com colegas, nos possibilitando a reflexão sobre pequenos detalhes que caracterizam os processos inclusivos.

Victor frequentava o $2^{\circ}$ período da Educação Infantil na Escola B. Para ele, o recreio não significava lanches e brincadeiras. Sempre nos pareceu solitário, permanecendo nas proximidades da sala. Seus deslocamentos sáo curtos e repetitivos, de um banco próximo à sala até a cantina onde busca água do filtro. Nas observaçóes, realizadas em dias letivos diferentes, registramos estes deslocamentos repetitivos do banco para o filtro. Também observamos que saiu da sala para o parque portando um objeto na mão. Na primeira observaçáo um copo e um pacote de lenços de papel. $\mathrm{Na}$ segunda, saiu da sala com a mochila na mão, e quando indagado pela professora pelo motivo respondeu-lhe: "gosto de olhar o desenho dela". As interaçôes com outras crianças são fortuitas, não há brincadeiras. Presenciamos uma cena no recreio, entre ele e um colega da sala, que, buscando pressioná-lo contra a parede, tenta retirar-lhe os óculos. Não há interferência de professoras. Lamentamos a ausência delas diante 
desta cena. A presença das crianças com corpos atingidos por diferenças nas escolas tem sido colocada como um ponto favorável para o exercício da convivência no grupo, pois

os colegas de classe têm a oportunidade de serem educados para a diversidade, a tolerância, a descoberta do outro [...]por outro lado, isto deverá prevenir o aparecimento de preconceitos que nós encontramos hoje nos adultos, sobretudo, naqueles que não tiveram a oportunidade de serem confrontados a uma experiência similar. (DE ANNA, 2003, p. 49)

A diretora e a professora nos contaram das dificuldades comunicativas com a mãe de Victor. Para elas a mãe 'escondia' o motivo e a verdadeira dificuldade visual dele; elas sabiam de informaçóes contadas por terceiros. Victor usava óculos com grau avançado.

Quando conversamos com Victor, foi visível seu desejo de falar, com um vocabulário elaborado na formação das frases. Disse-nos gostar da escola, da professora, mas que os colegas são "maldosos..., podem machucar". Pedimos que nos conte sobre isto, cala um pouco e diz, baixinho, que sua mãe "não deixa correr, pular, jogar futebol e bolinhas". Ainda nos conta que mora apenas com a mãe e, quando crescer "quer ser médico para cuidar das pessoas".

Percebemos na situação de Victor o impasse entre a escola e a família dificultando seu bem-estar na escola. Para além das deficiências, destacamos ter sido frequente escutarmos sobre dificuldades das professoras para acolher algumas máes. Estas atitudes maternas podem ser explicadas pelo temor em separar-se dos filhos e por razóes delicadas presentes no imaginário delas em sofrimento diante da problemática dos filhos. Por outro lado, quando as mães se sentem acolhidas pela instituiçáo, o efeito disto pode ser sentido na maneira intensa como os filhos passam a desfrutar do ambiente escolar. (RAHME, 2014).

\section{Considerações finais}

A garantia do acesso à educação de crianças outrora renegadas das escolas é um avanço. Os comentários apresentados neste artigo indicam as contradiçóes vivenciadas por professoras e alunos diante dos preceitos inclusivos, demonstrando assim, alguns desafios que se interpóem à educação inclusiva. A distância entre as políticas públicas inclusivas e a realidade das escolas é significativa. A constatação do distanciamento e o desencontro dos discursos dos sujeitos, não devem, aos nossos olhos, ser traduzidos pelo imobilismo. Há possibilidades educativas que podem emergir mesmo em situações de escassos recursos. Isto não é novidade. A novidade é a presença das crianças que carregam consigo alguma diferença, no corpo, nos sentidos, circulando pelas escolas. A urgência é uma reviravolta no olhar docente sobre as mesmas, quando 'déficits' precisam ser minimizados e possibilidades educativas buscadas. Isto pode ser original e desafiador.

A escolaridade das crianças em situação de deficiência ${ }^{7}$ não acontece de forma idêntica. Há pluralidade e complexidade nas histórias individuais. Não estamos 
a defender que as escolas, na situação na qual se encontram, sejam convocadas a responder pelas diversidades presentes. A educação inclusiva reclama dispositivos e ações políticas para sua efetivação principalmente quanto à valorização docente. Contudo, diante deste quadro, concordamos com Machado(2009) ao destacar que as dificuldades relativas à educaçáo inclusiva nas escolas públicas têm paralisado estas instituiçôes. Paralisação que contribui para a manutenção de um imaginário onde movimento, crescimento e mudanças só seriam possíveis diante de condições idealizadas e ilusórias.

As situações de fracasso são produzidas nos acontecimentos corriqueiros das escolas. Concebemos que, por parte dos docentes, ter consciência do fato e buscar flexibilidades nos percursos educativos das crianças com necessidades educativas especiais, são aspectos preciosos que podem significar para elas uma via de acesso a conhecimentos e significados partilhados nas salas de aula.

\section{Referências}

AINSCOW, M. Tornar a educação inclusiva: como essa tarefa deve ser conceituada? In: FÁVERO, O. et al.(Orgs.) Tornar a educaçáo inclusiva. Brasília: UNESCO, 2009. 220 p. Disponível em: <http://unesdoc.unesco. org/images/0018/001846/184683por.pdf>. Acesso em: 25 mar. 2016.

ALDERSON, P. As crianças como pesquisadoras: os efeitos dos direitos de participaçáo sobre a metodologia de pesquisa. Educ. Soc. Campinas, v. 26, n. 91. p. 419-442, maio-ago, 2005. Disponível em: <http://www.cedes. unicamp.br>. Acesso em: 10 set. 2014.

ANJOS, H; ANDRADE, E; PEREIRA, M. A inclusão escolar do ponto de vista dos professores: o processo de constituição de um discurso. Revista Brasileira de Educaçáo. v. 14, n. 40 jan./abr. 2009. p. 116-129. Disponível em: <http://www.scielo.br/pdf/rbedu/v14n40/v14n40a10.pdf>. Acesso em: 29 maio. 2015.

BARBOSA, E; SOUZA, V. A vivência de professores sobre o processo de inclusão: um estudo da perspectiva de psicologia histórico- cultural. Rev. Psicopedagogia, São Paulo, v. 27, n. 84, p. 353-362, 2010. Disponível em: $<$ http://pepsic.bvsalud.org/scielo.php?script=sci_arttext\&pid=S0103-84862010000300005\&lng=pt\&nrm=iso>. Acesso em: 10 mar. 2016.

BATISTA, M; ENUMO, S. Inclusão escolar e deficiência mental: analise da interação social entre companheiros. Estudos de Psicologia, 2004, v. 9, n. 1, p. 101-111. Disponível em: <http://www.scielo.br/pdf/epsic/ v9n1/22386.pdf>. Acesso em: 12 jun. 2015

BOGDAN, R.; BIKLEN, S. Investigaçáo qualitativa em educaçáo. 4. ed. Porto: Porto, 1994. 336 p.

DE ANNA, L. Un enfant gravement handicapé à l'école. In: BELMONT, B.; VÉRILLON, A. Diversité et handicap à l'école. Quelles pratiques éducatives pour tous? Paris: INRP et CTNERHI, 2003. p. 37-59.

DELALANDE, J. La cour de récréation. Pour une anthropologie de 1 'enfance. Rennes: Presses Universitaires de Rennes, 2001. 278 p.

DORZIAT, A. O profissional da inclusão escolar. Cadernos de Pesquisa. v. 43, n. 150. p. 986-1003, set./dez., 2013. Disponível em: <http://www.scielo.br/pdf/cp/v43n150/13.pdf>. Acesso em: 18 jun. 2015

FERREIRA, W. Inclusão e exclusão no Brasil: reflexôes sobre a formação docente dez anos após Salamanca. In: RODRIGUES, D. (Org). Inclusão e educação. Doze olhares sobre a educação inclusiva. São Paulo: Summus, 2006. p. 211-238

FREITAS, S. Sob a ótica da diversidade e da inclusão: discutindo a prática educativa com alunos com necessidades educacionais especiais e a formação docente. In: FREITAS, S. (Org.). Tendências contemporâneas de Inclusáo. Santa Maria : Editora da UFSM. 2008. 200 p.

GARDOU, C. Pensar a deficiência numa perspectiva inclusiva. Revista Lusófona de Educaçáo, v. 19. n. 19. p.13-23. 2011. Disponível em: <http://revistas.ulusofona.pt/index.php/rleducacao/article/view/2815>. Acesso em: 18 mar. 2016. 
GLAT, R.; FERREIRA, J. R. Panorama nacional da educaçáo inclusiva no Brasil. Disponível em: <http:// www.cnotinfor.pt/inclusiva/pdf/Educacao_inclusiva_Br_pt.pdf>. Acesso em: 23 jul. 2014.

GLAT, R.; BLANCO, L. Educação especial no contexto de uma educação inclusiva. In: GLAT, R. (Org). Educaçáo inclusiva: cultura e cotidiano escolar. Rio de Janeiro: Sette Letras, 2007. p. 15-35.

JANNUZZI, G. A educaçáo do deficiente no Brasil. Dos primórdios ao início do século XXI. Campinas, SP: Autores Associados, 2004. 243 p.

KASSAR, M. Educação especial na perspectiva da educação inclusiva: desafios da implantaçáo de uma política nacional. Educar em Revista, Curitiba, Brasil, n. 41, p. 61-79, jul./set., 2011. Disponível em: <http://www. scielo.br/pdf/er/n41/05.pdf>. Acesso em: 29 maio 2015.

LAPLANE, A. Uma analise das condições para a implementação de políticas de educação inclusiva no Brasil e na Inglaterra. Educ. Soc.,Campinas, v. 27, n. 96 - Especial, p. 689-715, out., 2006. Disponível em: <http:// www.cedes.unicamp>. Acesso em: 10 jun. 2015.

MACHADO, A. M. Educação inclusiva: de quem e de quais práticas estamos falando? In: BAPTISTA, C. R. (Org). Inclusấo e escolarizaçáo. Múltiplas perspectivas. Porto Alegre: Mediação, 2009. p. 127-134.

MAGALHÃES, A.; STOER, S. Inclusão social e a 'escola reclamada'. In: RODRIGUES, D. (Org.). Inclusão e educaçáo. Doze olhares sobre a educaçáo inclusiva. São Paulo: Summus, 2006.

MARCONI, M. A.; LAKATOS, E. M. Fundamentos de metodologia científica. 6. ed. São Paulo: Atlas, 2005. $315 \mathrm{p}$.

MATTOS, S. Inclusão/exclusão escolar e afetividade:repensando o fracasso escolar das crianças de classes populares. Educar em Revista, Curitiba, Brasil, n. 44., p.217-233, abr./jun. 2012. Disponível em: <http://ojs.c3sl. ufpr.br/ojs/index.php/educar/article/view/15757>. Acesso em: 25 maio 2015.

MÜLLER, L. Os profissionais do ensino fundamental e a educação inclusiva. Revista Conteúdo, Capivari, v. 1, n. 4, ago./dez., 2010, p. 61-71. Disponível em: <http://www.conteudo.org.br/index.php/conteudo/article/ viewFile/48/42>. Acesso em: 16 jun. 2015.

OLIVEIRA, A. Inclusão no Brasil: políticas públicas para o educando com necessidades educacionais especiais. In: GENARO, K. F.; LAMÔNICA, D. A.; BEVILACQUA, M. C. O processo de comunicação: contribuição para a formação de professores na inclusão de indivíduos com necessidades educacionais especiais. São José dos Campos: Pulso, 2006. p. 255-276.

OLIVEIRA, A.; DRAGO, S. A gestáo da inclusão escolar na rede municipal de são Paulo: algumas consideraçôes sobre o Programa Inclui. Ensaio: Avaliaçáo e Políticas Públicas em Educação. Rio de Janeiro, v. 20, n. 75, p. 347-372, abr./jun., 2012. Disponível em: <http://www.scielo.br/scielo.php?script=sci_arttext\&pi$\mathrm{d}=$ S0104-40362012000200007>. Acesso em: 3 jun. 2015.

PATTO, M. H. A produção do fracasso escolar. Histórias de submissão e rebeldia. 3 ed. São Paulo: Casa do Psicólogo, 2000. 454 p.

"Escolas cheias, cadeias vazias". Nota sobre as raízes ideológicas do pensamento educacional brasileiro. Estudos Avançados. São Paulo, v. 21, n. 61, dez., 2007, p. 243-266. Disponível em: <http://www.scielo.br/ scielo.php?script=sci_arttext\&pid=S010340142007000300016\&lng=en\&nrm=iso >. Acesso em: 5 jun. 2014.

PLAISANCE, E. Autrement capables. École, emploi, societé: pour l'inclusion des personnes handicapées. Paris: Autrement, 2009. 207 p.

PLETSCH, M. Repensando a inclusáo escolar. Diretrizes políticas, práticas curriculares e deficiência intelectual. Rio de Janeiro: Nau, 2010. 280 p.

RAHME, M. M. Laço social e educaçăo: um estudo sobre os efeitos do encontro com o outro no contexto escolar. Belo Horizonte ; Fino Traço, 2014. 426 p.

SACKS, O. Vendo vozes. Uma viagem ao mundo dos surdos. Tradução Laura Teixeira Mota. São Paulo: Companhia das Letras, 1998. $200 \mathrm{p}$.

SANCHES, I. Compreender, agir, mudar, incluir. Da investigação-acção e educação inclusiva. Revista Lusófona de Educaçáo. v. 5, 2005, 127-142. Disponível em: <http://revistas.ulusofona.pt/index.php/rleducacao/ article/view/1015/835>. Acesso em: 24 mar. 2016. 
Do 'aprender para fazer' ao 'aprender fazendo': as práticas de Educação inclusiva na escola. In: Revista Lusófona de Educaçáo. v. 19, n. 19, Jul. 2011. p. 63-83. Disponível em: http://revistas.ulusofona.pt/index.php/ rleducacao/article/view/2846, Acesso em: 11 jun. 2015.

SANT'ANA, I. Educação inclusiva: concepçôes de professores e diretores. Psicologia em Estudo, Maringá, v. 10, n. 2, p. 227-234, maio/ago., 2005. Disponível em: <http://www.scielo.br/pdf/pe/v10n2/v10n2a09.pdf>. Acesso em: 11 jun. 2015.

SARMENTO, M. J. Les cultures de l'enfance au carrefour de la seconde modernité. In: SIROTA, R. Éléments pour une sociologie de l'enfance. Rennes: Presses Universitaires de Rennes, 2006. p. 307-316.

SILVA, M. Dados de investigação em Ciências da Educação e Artes Visuais: testemunho para a construção da Escola Inclusiva. Revista Lusófona de Educaçáo, v. 25, p. 177-192, 2013. Disponível em: <http://revistas. ulusofona.pt/index.php/rleducacao/article/view/4386>. Acesso em: 15 jun. 2015.

SIROTA, R. Éléments pour une sociologie de l'enfance. 1 éd. Rennes: Presses Universitaires de Rennes, 2006. $325 \mathrm{p}$.

TESSARO, N. et al. Inclusão escolar: visão de alunos sem necessidades educativas especiais. Psicologia Escolar e Educacional, 2005. v. 9, n. 1, p. 105-115. Disponível em: <http://www.scielo.br/pdf/pee/v9n1/9n1a10.pdf>. Acesso em: 12 jun. 2015.

TREMBLAY, P. Inclusion scolaire. 1 éd. Dispositifs et pratiques pédagogiques. Bruxelles: De Boeck Éducation, 2012. $110 \mathrm{p}$.

VASQUES, C; MOSCHEN, S; GURSKI, R. Entre o texto e a vida: uma leitura sobre as políticas de educaçăo especial. Educ. Pesqui., São Paulo, v. 39, n. 1, p. 81-94, jan./mar. 2013. Disponível em: <http://www.scielo.br/ scielo.php>. Acesso em: 17 jun. 2015.

VILLE, I. RAVAUD, J. F. Personnes handicapées et situations de handicap. Paris: La documentation Française, 2003. $123 \mathrm{p}$.

\section{Notas}

${ }^{1}$ Abordamos neste trabalho os resultados parciais da pesquisa, uma vez que discutiremos os resultados relacionados a professoras e alunos. Tal recorte nos pareceu adequado, uma vez que apresentar os dados referentes á totalidade dos sujeitos envolvidos nos impóe um texto com dimensão maior que o esperado.

${ }^{2} \mathrm{~A}$ todos os sujeitos foi entregue o TCLE- termo de Consentimento livre e Esclarecido. As sete crianças envolvidas na pesquisa tiveram sua participaçáo autorizada através dos termos assinados por elas e por seus pais ou responsáveis.

${ }^{3} \mathrm{O}$ termo surge pela primeira vez no Relatório Warnock, elaborado pelo Reino Unido em 1978, considerado como documento responsável pela disseminação do termo (LAPLANE, 2006). Segundo Dussan ( 2011) o Relatório reafirma o significado de normalizar e se ocupa em discorrer sobre as condiçōes de vida comunitária que pessoas com NEE devem vivenciar como pertencentes à sociedade.

${ }^{4}$ Expressão utilizada pelos pesquisadores.

${ }^{5}$ Expressão utilizada pela equipe pedagógica da escola.

${ }^{6}$ A escola A tinha como recurso para aprendizagem de crianças que apresentavam "atraso escolar" o oferecimento de aulas de reforço de matemática e português, duas vezes por semana.

${ }^{7}$ A expressão em situação de deficiência é proposta por Isabelle Ville e Ravaud, isto é "para destacar o caráter conjuntural mais que natural da deficiência [...]. Nesta perspectiva, vê-se bem que a deficiência supera o campo da medicina e se situa no conjunto da esfera social"(2003, p. 8). 


\section{Correspondência}

Carla Mercês Rocha Jatobá Ferreira - Universidade Federal de Ouro Preto, CEAD, Campus Universitário, Morro do Cruzeiro, CEP: 35400-000 - Ouro Preto, Minas Gerais - Brasil.

E-mail: carlajatobaferreira@gmail.com - tatiflopes@yahoo.com.br

Recebido em 12 de agosto de 2015

Aprovado em 16 de abril de 2016 